\title{
Civil Engineering Collaboration
}

\author{
https://jcivil-upiyptk.org/ojs
}

2021 Vol. $6 \quad$ No. $2 \quad$ Hal: $64-67$

e-ISSN: 2615-5915

\section{Perencanaan Ulang Pondasi Pilar Jembatan Sikabu Kayu Gadang}

\author{
Nanda $^{1,}$ Maiyozzi Chairi ${ }^{2}$, Nofri Fu'adi Rahmat ${ }^{3}$ \\ 1,2,3Jurusan Teknik Sipil, Fakultas Teknik, Upi YPTK Padang \\ nanda_nanda@upiyptk.ac.id
}

\begin{abstract}
The construction of transportation facilities such as bridges plays an important role in the development of human resources today because more and more road users will use these facilities. The Sikabu Kayu Gadang Bridge has a span of 100 meters with a structure of precast concrete, abutments, pillars and a foundation of concrete and steel piles which inspired the authors to conduct research. In this type of selection, several things need to be considered, such as the load being carried and the location of the hard ground. Based on this, this study aims to analyze the deep foundation that can be applied to the project in the hope of getting more efficient results. Based on the re-planning, the bearing capacity of the foundation permit (Qall) is $1254.98 \mathrm{kN}$ with a diameter of $0.5 \mathrm{~m}$ and a depth of $20 \mathrm{~m}$. The permitted bearing capacity of the pile group (Qall) is $12795.46 \mathrm{kN}$ to withstand the loads acting on the superstructure. Bore Pile foundation logitudinal reinforcement $=10 \mathrm{D} 16$ and Bore Pile shear reinforcement $=Q 12-150 \mathrm{~mm}$.
\end{abstract}

Keywords: Bridge, Foundation, Bearing Capacity, Reinforcement.

\begin{abstract}
Abstrak
Pembangunan sarana transportasi seperti jembatan perperan penting dalam perkembangan sumber daya manusia saat ini sebab makin meningkatnya jumlah pengguna jalan yang akan menggunakan sarana tersebut. Jembatan Sikabu Kayu Gadang memiliki bentang 100 meter dstruktur atas beton pracetak, abutmen, pilar serta pondasi tiang pancang beton dan baja menjadi inspirasi penulis melakukan penelitian. Dalam pemilihan jenis pondasi perlu diperhatikan beberapa hal seperti beban yang dipikul pondasi dan letak tanah keras. Berdasarkan hal tersebut pada penelitian ini bertujuan untuk menganalisis pondasi dalam yang bisa diaplikasikan pada proyek tersebut dengan harapan mendapatkan hasil yang lebih efisien. Berdasarkan hasil perencanaan ulang didapatkan daya dukung ijin pondasi (Qall) sebesar $1254,98 \mathrm{kN}$ dengan diamater $0,5 \mathrm{~m}$ dan kedalaman 20m. Daya dukung ijin kelompok tiang (Qall) sebesar 12795,46 kN kuat menahan beban yang bekerja pada struktur atas. Tulangan logitudinal pondasi Bore Pile $=10 \mathrm{D} 16$ dan tulangan geser Bore Pile $=Q 12-150 \mathrm{~mm}$.
\end{abstract}

Kata Kunci : Jembatan, Pondasi, Daya Dukung, Tulangan.

(C) 2021 jcivil

\section{Pendahuluan}

Pembangunan sarana transportasi mempunyai peranan penting dalam perkembangan sumber daya manusia saat ini sebab makin meningkatnya jumlah pengguna jalan yang akan menggunakan sarana tersebut[1]. Salah satunya sarana transportasi yang akan penulis bahas kali ini adalah jembatan[2]. Jembatan sebagai sarana transportasi memiliki peranan penting dalam kelancaran pergerakan lalu lintas. Dimana jembatan berfungsi menghubungkan lintasan transportasi yang terpisah oleh sungai, danau, saluran,rawa, selat, saluran, jalan raya, jalan kereta api dan berbagai macam perlintasan lainnya[3].

Dilihat dari banyaknya pembangunan jembatan di Indonesia setiap tahunnya, dapat dikatakan bahwa pembangunan jembatan mengalami peningkatan. Salah satunya adalah Proyek Rehabilitasi/ Rekonstruksi Jembatan Sikabu Kayu Gadang Kec. Lubug Alung yang menjadi lokasi Kerja Praktek penulis selama dua bulan. Pekerjaan Pembangunan Jembatan Sikabu/Kayu Gadang ini berlokasi di antara Nagari Balah Hilia dan Nagari Lubuk Alung Kecamatan Lubuk Alung, dimana selama ini masyarakat hanya menggunakan jembatan lama yang sudah sering rusak. Maka dari itu Pemerintah Kota Padang Pariaman melalui dinas Badan Penanggulanagan Bencana Daerah (BPBD) Padang Pariaman merencanakan untuk membangun jembatan yang lebih baik.

Jembatan Sikabu Kayu Gadang memiliki bentang 100 meter dengan konsep gelagar menggunakan struktur atas beton pracetak, abutmen, pilar serta pondasi tiang pancang beton dan baja menjadi inspirasi penulis melakukan penelitian. Dalam pemilihan jenis pondasi perlu diperhatikan beberapa hal antara lain beban yang dipikul pondasi dan letak tanah keras[4],[5]. Berdasarkan hal tersebut pada penelitian ini bertujuan untuk menganalisis pondasi dalam yang bisa diaplikasikan pada proyek tersebut dengan harapan mendapatkan hasil yang lebih efisien. Karena dilihat dari beberapa penelitian terdahulu dengan merncanakan ulang, beberapa hasil diantaranya mendapatkan hasil yang lebih efisien dari segi pengerjaan dan biaya yang di butuhkan. 


\section{Metodologi Penelitian}

Langkah-langkah yang dilakukan dalam penelitian akan dijelaskan sebagai berikut :

1. Tahapan yang pertama adalah mengumpulkan data-data yang dibutuhkan dalam penelitian.

2. Rangkum beban struktur atas yang bekerja pada pondasi.

3. Menghitung daya dukung pondasi per kedalaman tanah

4. Menghitung dan menganalisis pondasi BorePile.

5. Menghitung dan menganalisis desain tulangan pondasi BorePile

6. Menghitung penurunan tiang tuanggal dan kelompok.

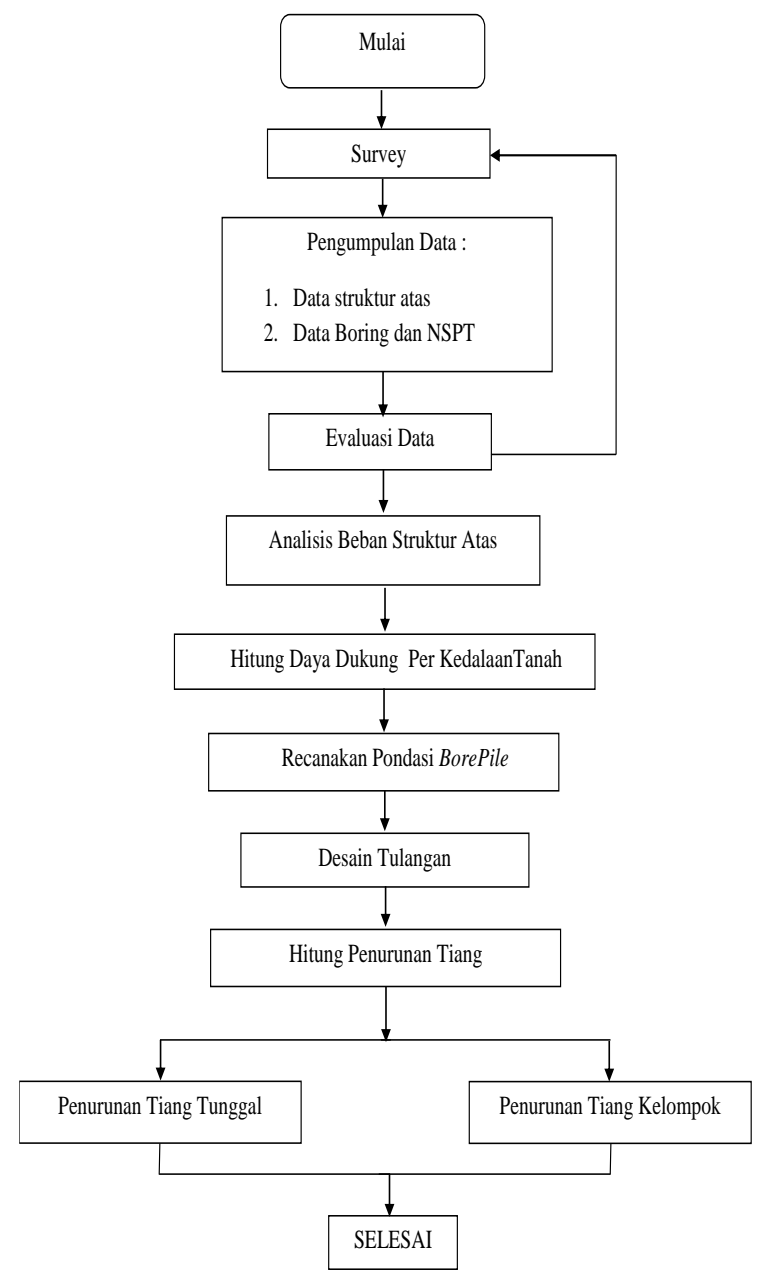

Gambar 1. Bagan Alir Penlitian

\section{Hasil dan Pembahasan}

3.1 Menghitung Kapasitas Daya Dukung Bored Pile Dari Data SPT (Standard Penetration Test)

Perhitungan kapasitas daya dukung pondasi bored pile dari data N-SPT menggunakan metode Mayerhoff dapat dilihat pada Tabel.1[6].

\begin{tabular}{ccc}
\multicolumn{3}{c}{ Tabel. 1 Data N-SPT } \\
\hline $\begin{array}{c}\text { Dept } \\
(m)\end{array}$ & Consistency & N-SPT \\
\hline
\end{tabular}

\begin{tabular}{ccc}
\hline 2 & Soft to medium & 6 \\
4 & Stiff & 9 \\
6 & Stiff & 10 \\
8 & Stiff & 12 \\
10 & Stiff & 14 \\
12 & Very Stiff & 17 \\
14 & Very Stiff & 28 \\
16 & Hard & 35 \\
18 & Hard & 49 \\
20 & Hard & 53 \\
22 & Hard & 44 \\
24 & Hard & 46 \\
\hline
\end{tabular}

Daya dukung ujung pondasi bored pile dari data N-SPT menggunakan metode Mayerhoff menggunakan pada Persamaan.1\&2[7].

$$
\begin{array}{ll}
\begin{array}{ll}
L & =
\end{array} & 20 \mathrm{~m} \\
D & =0,5 \mathrm{~m} \\
A p \quad & =0,19643 \mathrm{~m}^{2} \\
N_{60} \quad & =\frac{35+49+53+44}{4}=45,25 \\
& A p\left(0.4 P_{a} N_{60} \frac{L}{D}\right) \leq A p\left(4 P_{a} N_{60}\right) \\
& A p\left(0.4 P_{a} N_{60} \frac{L}{D}\right) \\
= & 0,19643\left(0.4 \times 100 \times 45.25 \frac{20}{0,5}\right) \\
= & 14221,42857 \mathrm{kN} \\
& A p\left(4 P_{a} N_{60}\right) \\
= & 0,19643(4 \times 100 \times 45,25) \\
= & 3555,3571 \mathrm{kN}
\end{array}
$$

Maka diambil nilai $Q p$ yang terendah yaitu $Q p=$ $3555,3571 \mathrm{kN}$. Daya dukung selimut dihitung dengan Persaman.3[8].

$$
\begin{aligned}
Q s= & p . L . f a v \\
& \text { Dimana }: f_{a v}=0.02 p a\left(\underline{N}_{60}\right) \\
& \\
Q s \quad= & p \cdot L . f a v \\
= & 1,571428576 \times 20 \times 46,6 \\
= & 1464,571 \mathrm{kN}
\end{aligned}
$$

Setelah didapatkan nilai daya dukung ujung dan selimut pondasi maka dapat dihitung daya dukung ultimit pada Persamaan.4[9].

$$
\begin{aligned}
Q u & =Q p+Q s \\
& =3555,3571 \mathrm{kN}+1464,571 \mathrm{kN} \\
& =5019,93 \mathrm{kN}
\end{aligned}
$$

Daya dukung ijing :

$$
\begin{aligned}
\text { Qall } & =Q u / F S \\
& =5019,93 / 4 \\
& =1254,98 \mathrm{kN}
\end{aligned}
$$

\subsection{Perencanan Kelompok Tiang}

Perencaaan kelompok tiang bertujuan untuk menentukan kombinasi pondasi pada pile cap. 


$$
\begin{aligned}
& D \quad=0,5 \mathrm{~m} \\
& L=20 \mathrm{~m} \\
& n \quad=3 \times 5 \\
& =15 \\
& \text { d }=2,5 \mathrm{D} \\
& =2,5(0,5) \\
& =1,25 \gg 1,4 \mathrm{~m}
\end{aligned}
$$

Tepi Poer :

$$
\begin{aligned}
& =1 / 2 D \\
& =1 / 2 \cdot 1,4 \\
& =0,7 \mathrm{~m} \\
& =4(d)+D \\
& =4(1,4)+0,5 \\
& =6,1 \mathrm{~m} \\
& =2(d)+D \\
& =2(1,4)+0,5 \\
& =3,3 \mathrm{~m}
\end{aligned}
$$$$
\text { Lg } \quad=4(d)+D
$$$$
B g \quad=2(d)+D
$$

Dari perhitungan tesebut, selanjutnya dapatkan a. Tulangan Pile Cap Arah X

digambarkan dimensi kelompok tiang bor dan pilecap untuk melihat desian yang akan digunakan, maka pada Gambar. 2.

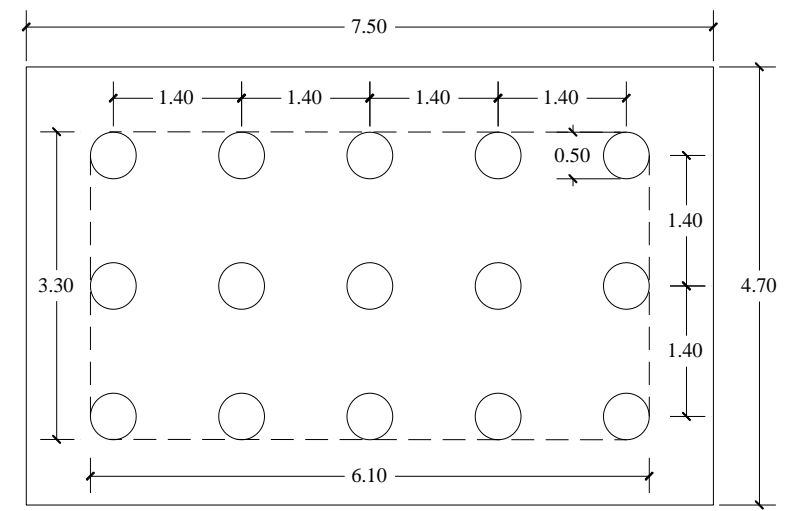

Gambar. 2. Dimensi Group Pile

\subsection{Efesiensi Kelompok Tiang}

Efesiensi kelompok tiang menggunakan Persamaan.5 yang disarankan oleh Converse-Labare[10],[11].

$$
\begin{array}{ll}
E g & =1-\Theta \frac{(n-1) m+(m-1) n}{90 . m \cdot n} \\
\mathrm{~m} & =3 \\
\mathrm{n} & =5 \\
\mathrm{~s} & =1,4 \mathrm{~m} \\
\mathrm{~d} & =0,5 \mathrm{~m} \\
\Theta & =\tan ^{-1} \frac{d}{S} \\
& =\tan ^{-1} \frac{0,5}{1,4} \\
& =19,65 \\
E g & =1-\Theta \frac{(n-1) m+(m-1) n}{90 . m . n} \\
& =1-19,65 \frac{(5-1) 3+(3-1) 5}{90.3 .5} \\
& =0,67971546
\end{array}
$$

dukung pada kelompok tiang. Hal ini dapat dilihat pada perhitungan dibawah ini[12].

Diketahui :

$$
\begin{aligned}
P & =4795,373 \mathrm{kN} \\
n & =15 \\
Q u & =5019,93 \mathrm{kN} \\
Q g & =E g \times n \times Q u l l \\
& =0,67971546 \times 15 \times 5019,93 \mathrm{kN} \\
& =51181,85 \mathrm{kN} \\
Q_{\text {all }} & =Q g / F S \\
& =51181,85 \mathrm{Kn} / 4 \\
& =12795,46 \mathrm{kN}
\end{aligned}
$$

Cek struktur : $\quad Q_{\text {all }}>P$

$$
12795,4 \mathrm{kN}>4795,373 \mathrm{kN} \ldots . .(\text { Aman })
$$

\subsection{Desain Tulangan Pile Cap}

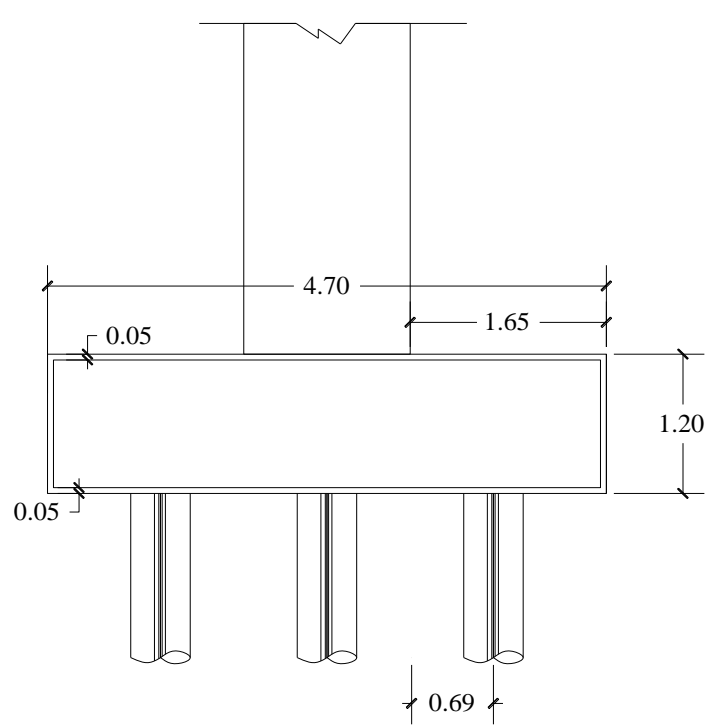

Gambar 3 . Rencana PileCap Arah X

$$
=7,5 \mathrm{~m}
$$

\subsection{Gambar Penulangan}

Setelah hasil simulasi dalam desain tulangan pile cap, maka proses dilanjutkan dalam menggambarkan penulangan yang dapat dilihat pada Gambar.4[14].

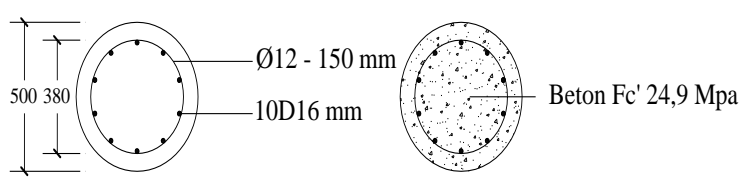

\subsection{Daya Dukung Kelompok Tiang}

Setelah melakukan pengukuran efesiensi kelompok tiang, maka proses dilanjutkan untuk mengukur daya 


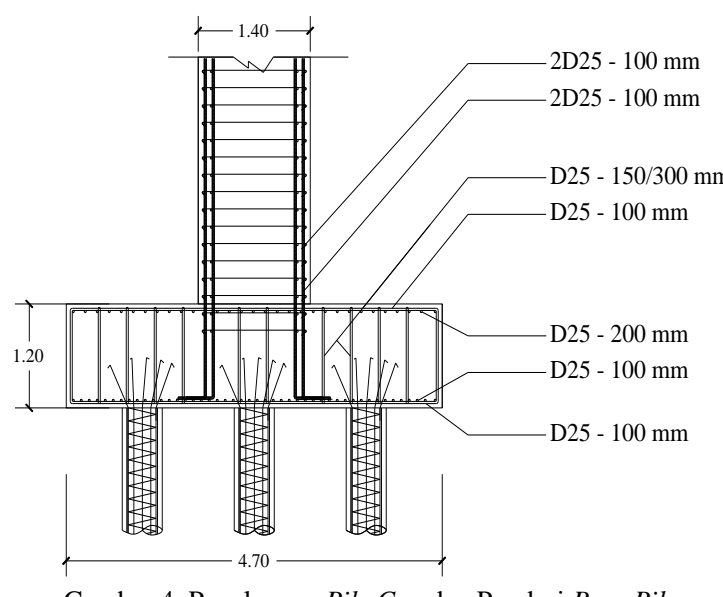

Gambar 4. Penulangan Pile Cap dan Pondasi Bore Pile

\section{Kesimpulan}

Berdasarkan hasil perhitungan perencanaan ulang pondasi pilar jembatan pada proyek Rehabilitasi Rekonstruksi Jembatan Sikabu Kayu Gadang didaptkan bahwa Daya dukung sisi pondasi ( $Q S$ ) sebesar 1464,571 $\mathrm{kN}$, daya dukung ujung $(Q p)$ sebesar $3555,3571 \mathrm{kN}$, daya dukung ultimit $(Q u)$ sebesar $5019,93 \mathrm{kN}$, sehingga diadapat daya dukung ijin pondasi (Qall) sebesar $1254,98 \mathrm{kN}$ dengan diamater $0,5 \mathrm{~m}$ dan kedalaman 20 $\mathrm{m}$. Daya dukung ijin kelompok tiang (Qall) sebesar $12795,46 \mathrm{kN}$ kuat menahan beban yang bekerja $(P)$ sebesar 3906,81 kN dengan formasi 3x5 (15 tiang) serta [12 nilai efesisensi tiang kelompok $(E g)=0,67971546$.

Tulangan tulangan lentur Pile Cap arah X = D25-100 $\mathrm{mm}$, tulangan susut arah $\mathrm{X}=\mathrm{D} 25-150 \mathrm{~mm}$, tulangan lentur arah $\mathrm{Y}=\mathrm{D} 25-100 \mathrm{~mm}$, tulangan susut arah $\mathrm{Y}=$ D25 - $200 \mathrm{~mm}$ dan tulangan geser $=$ D25 $-150 / 350$ $\mathrm{mm}$. Tulangan logitudinal pondasi Bore Pile $=10 \mathrm{D} 16$ dan tulangan geser Bore Pile $=$ Q $12-150 \mathrm{~mm}$. Besar penurunan tiang tunggal adalah $34,98 \mathrm{~mm}$ dan penurunan kelompok tiang sebesar $52,3 \mathrm{~mm}$.

\section{Daftar Rujukan}

[1] BMS. (1992). Bridge Design Manual Volume 1. Directorate General og Highways Ministry of Public Works Republic of Indonesia.

[2] BMS. (1992). Bridge Design Manual Volume 2. Directorate General og Highways Ministry of Public Works Republic of Indonesia.

[3] Bowles, Joseph E.(1993) Analisa dan Desain Fondasi Jilid I dan II. Jakarta : Erlangga.

[4] Darwis. (2018). Dasar-dasar Mekanika Tanah. Yogyakarta : Pena Indis.

[5] Das, Braja M. (2007). Principles Of Foundation Engineering. United Kingdom : Cengange Learning

[6] Direktorat Jendral Bina Marga. Petunjuk Teknis Pengujian Tanah. Kementrian Pekerjaan Umum Dan Perumahan Rakyat. Erny Harianti \& Anugrah Pamungkas.(2013). Desain Pondasi Tahan Gempa. Yogyakarta : Penerbit Andi

[8] Hakam, Abdul. (2008). Rekayasa Pondasi. Padang : CV Bintang Grafika.

[9] Ilham, M Noer. (2008) Analisis Fondasi Pier.Yogyakarta : MNI-EC

[10] RSNI T-02(2005). Standar Pembebanan Untuk Jembatan. Badan Litbang Departemen Pekerjaan Umum.

[11] RSNI T-12. (2004). Perencanaan Struktur Beton Untuk Jembatan. Badan Strandarisasi Nasional.

[12] Setiawan, Agus. (2016). Perancangan Struktur Beton Bertulang. Jakarta : Erlangga

[13] SNI 03-2847(2002). Tata Cara Perhitungan Struktur Beton Untuk Bangunan Gedung. Bandung

[14] SNI 2847.(2013). Persyaratan Beton Struktural Untuk Bangunan Gedung. Jakarta: Gd. Manggala Wanabakti 